\title{
Improving insight in modal choice determinants: an approach towards more sustainable transport
}

\author{
J. Hollevoet, A. De Witte \& C. Macharis \\ Department MOSI-Transport \& Logistics, \\ Vrije Universiteit Brussel, Belgium
}

\begin{abstract}
Understanding which determinants influence modal choice is important towards developing more sustainable transport systems. An improved knowledge about these factors is vital to tackle our current mobility problems in a more efficient and sustainable way. In order to assist to the understanding and modelling of modal choice decisions a review on modal choice and its determinants is carried out. The data collection strategy for this review is mainly based on a computerized search guided by the search term 'modal choice' and mostly covers the last two decades. First of all, it was found that researchers too often rely on a unimodal approach when they study modal choice. This leads to an underestimation of access and exit modes by neglecting other travel modes, which are mainly the softer modes (walking and cycling). Taking into account the sequence of modes within a single trip is therefore needed to analyze daily mobility in a more sustainable and realistic way. Secondly, the review clearly showed that modal choice is determined by a whole range of factors, which are interrelated to a larger or smaller extent. It is thus often the result of a very compound choice process that can take place consciously or unconsciously and that includes objective as well as subjective determinants. In this paper, we identify and structure the determinants of importance influencing the modal choice decision. Moreover, improving insight in these influencing factors can assist to develop policy measures that are better adjusted to the current mobility trends in order to create a modal shift towards more sustainable transport modes and thus reduce the environmental impact.
\end{abstract}

Keywords: modal choice, sustainable transport, determinants, travel behaviour. 


\section{Introduction}

Mobility is of growing importance in our daily lives. A typical day consists of a chain of activities, which are often located at different places. A rising demand in mobility is created. In reality, the car is too often the indisputable dominant transport mode. Between 1995 and 2006, car ownership levels in the EU-27 increased by $22 \%$ (or 52 million cars), the use of passenger cars increased by $18 \%$ [1]. The dominance of a polluting, unsustainable transport mode like the car, with too many negative side-effects, cannot be ignored in further policy and planning. Currently, a growing awareness of the rising mobility needs and its negative effects emerges. These effects are not only situated in the environmental domain, but there is also an economical and societal impact (e.g. liveability) of increasing mobility. This has opened the debate on how to manage our current and future mobility in a more sustainable way. In order to take adequate policy measures to guide our current mobility towards a more sustainable one, a deeper understanding of the actual travel behaviour of people and their modal choices is necessary [2].

Many studies have already been conducted to investigate modal choice. However, in literature, no uniform definition of modal choice is given. Depending on the scope of the research, different types of influencing determinants are in use. A complete overview cannot be found in literature. In this way, it can be very useful to create more insight in all determinants influencing modal choice. Understanding travel behaviour and modal choice is of crucial importance towards understanding mobility patterns. Further insight in the modal choice gives us possibilities of dealing more correctly with this complex topic. The aim of this review is to provide a better insight and a broader outlook on the concept of modal choice by elaborating a multi-disciplinary framework that contributes to an improved knowledge on the different modal choice determinants. This can lead to a better knowledge of these determinants and could influence further policy making. In this way, a possible reduction of the negative impact of mobility on both local and global environment can be achieved.

The outline of this paper is as follows: in the next section (section 2) the search strategy will be explained. Next, in section 3 , attention will be paid to how modal choice is defined in different research studies and in section 4 on what different determinants play their role. This is followed by a discussion on the modal choice concept and its influencing factors (section 5). Finally, section 6 will provide the main conclusions as well as some recommendations.

\section{Methodology}

For this review, all types of researches (modelling, empirical, surveys, etc.) concerning passenger travel behaviour with emphasis on modal choice were taken in consideration. The following key questions were addressed:

- How is modal choice defined?

- Which factors determine modal choice in what way? 
The data collection is for the most part based on a computerized search. Papers were mainly retrieved by tracking cited references and by tracking ecatalogues. This paper mostly covers articles from the last two decades. Several sources were used to search for literature: web-based search tools (V-spaces and Article database, e-sources), the VUBIS library e-catalogue from the university library of VUB (Vrije Universiteit Brussel) and ordinary web-search robots (e.g. Google Scholar). From the resulting output, relevant hits were filtered out for further analysis. Then, articles were screened on their relevance with regard to modal choice definition and determinants. This resulted in 37 articles being retained for further analysis and processed for this review.

\section{Definition of modal choice}

In literature, no uniform definition on modal choice is given or used. However, in many studies a definition can be derived from the type of determinants studied to examine modal choice. In this way, three different approaches can be distinguished: a rationalist approach, a socio-geographical approach and a psychological approach. Each of these approaches has its own specific character and focus to study a complex process like modal choice.

The rationalist approach can be seen as the mainstream approach to study modal choice based on the assumption that travellers take decisions based on utility maximization attained by minimizing travel time and costs [3]. This microeconomic approach implies that individuals behave perfectly rational dealing with all kinds of available information. In this way, a person confronted with different alternatives acts rationally and will eventually select the alternative with the highest utility. Many researches on modal choice in literature based on this discrete choice analysis have been conducted [4-7]. The determinants studied in these researches are mostly associated with travel time and costs leading to modal choice definitions based on objective and rational components only.

The socio-geographical approach explicitly introduces a spatial component into the modal choice decision process and starts from the activity schedule of individuals or households to explain modal choice [8-10]. This approach treats the demand for travel as a derived demand: people are presumed to travel not for the sake of it, but in order to pursue activities distributed in space and time. The introduction of time and space into the modal choice decision process leads to the inclusion of a spatial component in the modal choice definitions.

The psychological approach aims at explaining modal choice by the study of attitudes of individuals with regard to the available transport means. In order to understand the process behind travel mode decisions psychologist have developed the attitudinal approach. Important elements are the concepts of intentions and habits. Already in the seventies, there was awareness that subjective factors also play a role in determining modal choice. Lovelock [11] pointed out that modal choice is determined by psychological variables as well as the travellers' need for information if he/she is to evaluate all alternatives realistically. Many researchers postulate that modal choice should not only be 
studied based on objective measurements, but should also take into account subjective aspects $[12,13]$.

These three approaches together bring us to the presentation of a multidisciplinary modal choice definition, which is often lacking in literature. Based on this review's findings, modal choice could be defined as the decision process to choose between different transportation alternatives determined by a combination of individual socio-demographic factors and spatial characteristics, and influenced by psychological factors. Alternatives could refer to one single mode, but also to a combination of travel modes (motorized as well as nonmotorized). One can distinguish both objectively measured determinants (like socio-demographic and spatial factors) as well as subjective factors (e.g. sociopsychological factors like perceptions, attitudes, preferences and habits) determining the perception of the objective ones. In the next section, these influencing factors will be treated and further explained.

\section{Determinants of modal choice}

In literature, many different determinants from many disciplines are playing their role in the modal choice decision. For this paper, 23 important determinants were selected and structured. Bundling all these determinants into a framework is of great importance in understanding the complexity of modal choice decisions. As different disciplines are included in the modal choice process, it is important to note that a multidisciplinary perspective will be chosen. Taking into account the three main approaches to study modal choice, one comes to the concept of modal choice as presented in figure 1 . This figure, using the three approaches, becomes complete when adding an extra component specific to journeys and travel modes. To create substantial insight in the modal choice decision process, one can start working from this framework. It is important to note that a certain interrelation between the determinants from the different pillars is present to a smaller or larger extent.

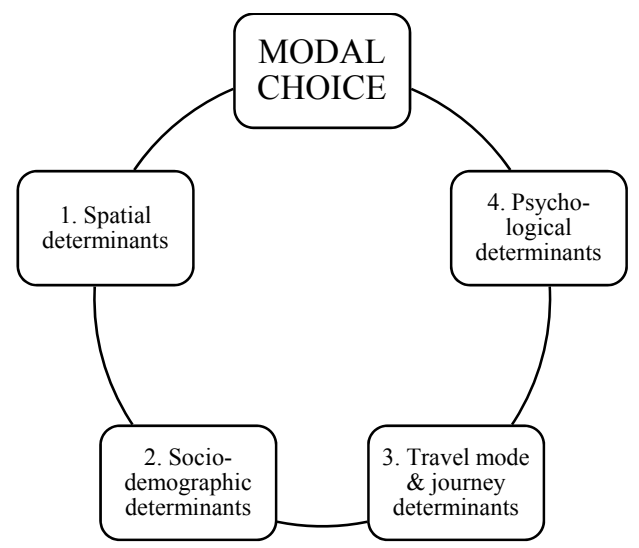

Figure 1: $\quad$ Framework presenting modal choice determinants. 


\subsection{Spatial determinants}

This pillar treats the spatial determinants influencing modal choice. Creating more insight in these factors can be of great importance towards more sustainable transport. The determinants of interest here are: density, proximity to infrastructure, parking, frequency of public transport, diversity and interchange.

Here, density is considered as the ratio inhabitants/built-up area. Urban areas (higher density) are better served with public transport than rural areas (lower density). According to Kenworthy and Laube [14], density is a key determinant in modal choice: high densities tend to be associated with lower average trip distances for all modes, improved public transport and enhanced possibility of walking and cycling. One can conclude that public transport is more used in large metropolitan areas compared to smaller ones $[15,16]$. The urban location of a household has a positive effect on the use of public transport [17].

Proximity to infrastructure refers to the availability of road networks on one hand and to public transport infrastructure on the other hand. This aspect plays a determining role in the modal choice decision, because of its importance in the availability of alternative modes. It is closely related to other spatial characteristics like density and diversity, both at the origin and destination side of the trip. According to Limtanakool et al. [16], the availability of a public transport-stop increases public transport use, although for the modal choice decision the proximity to a public transport-stop at the destination side is of greater importance and determining than at the origin side. Kenworthy and Laube [14] mention that auto use increases significantly with increasing road availability.

The availability of parking does have an important impact on modal choice, especially in highly dense areas [12]. People are stimulated to use their car (irrespective of whether it is quicker or not than public transport) when they are guaranteed of having a (free) parking space at work [14, 18-21].

The frequency of public transport plays a crucial role in the usage pattern and in the availability of public transport, therefore it influences modal choice. The frequency and efficiency of a public transport system is mainly related to city density [15]. In big metropolitan areas, well-organized public transport is mostly available.

Diversity can be seen as a mixed land-use in terms of a diverse pattern of residence, commerce, institutions, green space, industry and transport infrastructure accommodated by the neighbourhood. According to Cervero [6] land-use mixtures at both origin and destination side lower the probability of driving alone or ride-sharing in contrast of taking public transport, and vice versa.

According to a study, conducted by De Witte et al. [22], the second most important reason for car users to use their car is a bad public transport connection. There is a general resistance among people to interchange [13]. This is being confirmed by de Vasconcellos [20] where a limited supply of integrated public transport modes reduces the use of it. 


\subsection{Socio-demographic determinants}

In this pillar the different socio-demographic determinants with influence on modal choice will be explained. These factors are: gender, age, employment, income, lifestyle, education, household size and car availability.

Car availability is by far the most important determinant influencing modal choice. It has long been recognized that car availability and thus car ownership is a primary determinant of modal choice [23]: the probability of selecting a car for travel increases with increasing amount of cars per driver in a household [10, 14, $16,24]$. Dwelling in a zero-car household is strongly related with transit dependency [6].

No real consensus about gender playing a decisive role in modal choice can be found in the consulted literature. Some studies report that women are more likely to use the car because of the higher proportion of household errands in combination with their home-work commutes which makes public transport less convenient [25]. Other studies report that men are more likely to use the car while women are more dependent on public transport [2, 16, 21, 26]. It appears that the interdependency between gender and other factors, like household composition, employment status, etc. is more determining for decisions on transport modes.

Employment determines the availability of a car indirectly through income, but for commuting the mobility policy pursued by the company definitely plays a role. The use of public transport passes gives more possibilities to employees using transit, whereas providing a company car leads to a further increase in the use of private transport modes with a big decrease in public transport use [21, 22].

With regard to modal choice it was found that choosing solo-auto mode over shared-riding or transit is more likely among higher income levels [27]. For trip chains, people with higher income make more complex work tours, for which the dominant mode is the car [19]. In general, individuals living in higher income zones are less likely to use transit and to walk [28]. Especially lower incomes tend to be more influenced by the price of transport, which stimulates their mobility decisions according to this criterion [13]. People of lower income level face severe restrictions to travel because of less access to cars and lower mobility levels [20].

An individual's life-style choices are determining for his/her social status, which is in turn determining for his/her access to different travel modes. Lifestyle choices include decisions on education and occupation, which are both related to income and car ownership. Higher educated people are more likely to have higher income levels and to use the car to go to work [29]. According to the view of Scheiner and Holz-Rau [30], individual life-styles play an important role in determining travel modes. Life-style does influence modal choice, but the influence of objective socio-economic (age, gender, household type, employment, etc.) characteristics exceed the influence of subjective lifestyles [31]. 
In literature, there seems to be no real consensus on the impact of age on modal choice. Some studies found that older people tend to use public transport more often, while others state that car use increases together with age $[2,17,28]$.

For education too, no consent was found in literature. According to Pickery [29] higher educated people are more likely to have higher income levels and as a result they are more prone to use the car to go to work. This is denied by other authors like Limtanakool et al. [16] and Schwanen et al. [26] who state that higher educated people use public transport more frequently for commuting than the car.

With regard to household type, in general it is found in literature that as the size of a household increases, there is a higher probability of travelling by car $[10,32]$. Especially the presence of children in a family increases the utility of car use, which has a significant negative impact on public transport use in turn $[16,17]$.

\subsection{Travel mode and journey determinants}

In this pillar the determinants specific to the travel mode taken or the journey undertaken are further explained, namely: distance, travel time, travel cost, trip chaining, departure time and the travel motive.

The travel motive is an important factor since it initiates every journey. In literature four main travel motives can be distinguished: work-commuting trips, school-commuting trips, business journeys and leisure journeys.

Distance, travel time and travel cost are directly related to each other. The longer the distance, the longer the travel time and the more it will cost. Travel time is, according to many studies, an important determinant of modal choice $[27,33]$. Since different people have different values of time and time budgets, travel time can be valued differently depending on the travel motive. Travellers seem to be more sensitive to out-of-vehicle travel time than in-vehicle travel time [2].

Besides the travel time, also travel cost plays a significant role in modal choice $[12,27]$. Consumers are sensitive to changes in price, but the extent depends on several factors, like the purpose of the trip [34]. Costs for travelling by car are underestimated compared to the price of public transport for the same journey [22].

According to Nurul Habit et al. [28], modal choice is determined by all trips in the chain, except if the first trip is a work trip, then this trip is determining for modal choice. In a recent study of Currie and Delbosc [35], public transport chains were generally found to be more complex than those undertaken by car, explaining why car is usually favoured when making trip chains. An increasing number of intermediate stops on the home-activity-home tour indeed increases the likelihood of driving [28]. O'Fallon et al. [21] report that car use is increased because of multiple destinations when having to drop off children.

The trip timing, with regard to the departure time, is interconnected with modal choice. Public transport is less attractive during off-peak due to lower 
service levels whereas car is more attractive during off-peak due to lower traffic congestion [28].

\subsection{Psychological determinants}

Different psychological, subjective factors influence modal choice, and its objective determinants in a certain way. In this review, three factors will be explained: habits, experiences and perceptions.

Strong habit travellers use less compensatory choice rules than weak habit participants [36]; their travel decision is only based on a fraction of the information available. Switching to other travel modes requires learning new routines.

The way in which users have experienced a certain travel mode will help them appreciating a particular travel means and will play a decisive role in their modal choice. A positive or negative experience in the past will determine the modal choice process in the present. Also, network experiences can influence modal choice. The higher the user's network experience, based on the length of time the user has used the main route to go to work, the higher the probability of using a private transport mode to go to work [32].

The perception of individuals with respect to the different means of travel is of importance in the modal choice decision. Van Acker et al. [31] mention that preferences are based on attitudes and perceptions, according to Goodwin et al. [24] quality perception is determined by the person's own history. Besides the perception of the different travel modes, time and price can both be perceived differently for alternative transport modes.

\section{Discussion}

We have seen that many different determinants play their role in influencing the modal choice decision process. In a more classical view, the focus lies more on rational and economical factors while in some cases objective spatial components and sometimes subjective factors stemming from psychology are taken into account.

The car is without doubt the dominant travel mode for all travel motives over the last decades. Nevertheless, for commuting to work a large share of people use public transport and for this travel need the share is considerably higher than for the other travel motives. Next to car ownership and the travel motive, many other determinants each have their specific influence on the modal choice and are sometimes mutually affecting each other. Employment, for instance, has a certain influence on modal choice often being influenced by the mobility policy pursued by the company.

Out of the spatial determinants, it can be seen that many factors influence the modal choice decision process. All these factors are in a way interrelated to each other where an emphasis can be put on the density factor whose importance cannot be ignored: higher density leads mostly to a better proximity of infrastructure, an increase in the frequency of public transport and to a lowering 
of car parking spaces. Understanding these factors in the overall discussion with regard to choosing transportation modes is of great importance. As found in literature, higher urban densities at the workplace have a consistent positive effect on the likelihood of choosing public transport and walk modes. In that way, higher frequencies raise the relative efficiency of public transport to other transport modes and by that the share of public transport [15].

In general, people living in suburban or rural areas consider less alternative travel modes and make more use of car. Also, the supply of public transport can be measured by taking into account the distance to public transport (nodes) for the surrounding area and the population residing in these areas. Thereby, a direct insight on the use of public transport is created. Especially for trip chains, proximity or availability to infrastructure is determining for the modal choice. Out of literature research, if no or insufficient public transport is present for at least one trip in a longer chain, trips will generally be made by car instead of using public transport [33]. Besides density, proximity to infrastructure, frequency of public transport, etc., also parking facilities and interchange have their impact on the modal choice. Brown et al. [25] conclude that lowering the parking lots will raise the use of public transport in comparison to car use. As we know out of literature, a general resistance among people to interchange exists.

However, one can have an impact on influencing public transport through a better understanding of the spatial factors, it needs to be nuanced that besides these factors also more complex determinants influence modal choice: e.g. psychological factors or complex 'ambiguous' factors like the price of transport, income, household size, etc. Focussing on the price of public transport, several studies about improving public transport indicate that only a limited share of car drivers would want public transport to be made less expensive in order to use it [22]. Rietveld [37] warns for substantial substitution possibilities between public transport on one hand and biking and walking on the other hand. A decrease in public transport-fares will lead to a reduction in the use of non-motorized transport modes such as walking and biking. Thus, although regulations could interfere with car pricing policies, the desired result will not necessarily 'take control'. Also for car availability, it might be hard to control this because the interests are of paramount importance for too many people. Though, changing policies (which is currently being tested/done in some cities) through car pricing etc. can be a viable way of creating more control of congestion.

\section{Conclusions and recommendations}

A first conclusion drawn from this paper is that modal choice is a very complex decision process. In many cases, a unimodal approach is being used only considering the main transport mode used during a journey hereby neglecting other transport modes like access and exit modes, typically walking and cycling. This approach neglects the occurrence of trip chains and intermodality, which have grown to be more important in our daily mobility as people strive for more efficient ways to join their activities throughout the day. In addition, modal choice is often represented as a competition between several modes to make a 
journey in an efficient (in terms of time and costs) and sustainable way. Due to the complex nature of the research topic an often too narrow approach of modal choice is commonly used in travel behaviour.

Other issues concern the way modal choice is defined and which determinants are taken into account to study it. Based on the findings of this review, it can be concluded that there is no uniform definition, nor approach to study the concept of modal choice. The approach used mainly depends on the research perspective. Following a multi-disciplinary perspective, we propose a common definition of modal choice where modal choice is defined as the decision process to choose between different transport alternatives, which is determined by a combination of individual socio-demographic factors and spatial characteristics, and influenced by psychological factors.

It was also found that modal choice is influenced by a wide range of determinants, both objective and subjective ones, being interrelated to a larger or smaller extent and that modal choice can take place consciously or unconsciously. In order to contribute to an improved knowledge on the different modal choice determinants, a multi-disciplinary concept was suggested dealing with all influencing factors. It is vital to stress the importance of taking the subjective component into account when studying modal choice.

The improved insight in the influencing factors of the presented concept can assist policy makers towards creating more sustainable transport systems. In this way, policy measures that are better adjusted to the current mobility trends could be taken in order to create a modal shift towards more sustainable transport. Further research on these specific influenceable determinants can improve the knowledge on modal choice.

\section{References}

[1] EEA, Report 3. 'TERM 2008: indicators tracking transport and environment in the European Union', website European Environment Agency, 2009.

[2] Bhat C., 'Analysis of travel mode and departure time choice for urban shopping trips', Transportation Research Part B: Methodological, 32 (6), pp. $361-371,1998$.

[3] Shen J., Y. Sakata \& Y. Hashimoto, 'The influence of environmental deterioration and network improvement on transport modal choice', Environmental Science \& Policy, 12 (3), pp. 338 - 346, 2009.

[4] McFadden, D., 'The measurement of urban travel demand', Journal of Public Economics, 3, pp. 303-328, 1974.

[5] Ben-Akiva M. \& S. Lerman, Discrete choice analysis: Theory and application to travel demand. MIT Press, Cambridge, 1985

[6] Cervero R., 'Built environments and mode choice: toward a normative framework', Transportation Research Part D: Transport and Environment, 7 (4), pp. $265-284,2002$. 
[7] Shen J. Sakata, Y. \& Y. Hashimoto, 'Is individual environmental consciousness one of the determinants in transport mode choice?', Applied Economics, 40(10), pp. 1229-1239, 2008.

[8] Bhat, C. \& S. Singh, 'A comprehensive daily activity-travel generation model system for workers', Transportation Research Part A, 34, pp. 1-22, 2000.

[9] Axhausen, K., 'A dynamic understanding of travel demand: a sketch', Arbeitsbericht Verkehrs- und Raumplanung, 119, Institut für Verkehrsplanung und Transportsysteme (IVT), ETH Zürich, 2002.

[10] Cirillo, C. \& K. Axhausen, 'Comparing urban activity travel behaviour', Transportation Research Board, 81 ${ }^{\text {th }}$ Annual Meeting, January 13-17, Washington D.C., 27p, 2002.

[11] Lovelock C., 'Modeling the modal choice decision process', Transportation, 4, pp. 253-265, 1975.

[12] Kajita Y., S. Toi, T. Chishaki \& A. Matsuoka, 'Structural mechanism of modal choice based on the linked structure of trip purpose and transportation choice', Memoirs of the Faculty of Engineering, Kyushu University; 64 (1), 2004.

[13] Hine, J. \& J. Scott, 'Seamless, accessible travel: users' views of the public transport journey and interchange', Transport Policy, 7, pp. 217-226, 2000.

[14] Kenworthy J. \& F. Laube, 'Automobile dependence in cities: an international comparison of urban transport and land use patterns with implications for sustainability', Environmental Impact Assessment Review, 16, pp. 279 - 308, 1996.

[15] Camagni, R., M.C. Gibelli \& P. Rigamonti, 'Urban mobility and urban form: the social and environmental costs of different patterns of urban expansion', Ecological Economics, 40 (2), pp. 199 - 216, 2002.

[16] Limtanakool N., M. Dijst \& T. Schwanen, 'The influence of socioeconomic characteristics, land use and travel time considerations on mode choice for medium- and longer-distance trips', Journal of Transport Geography, 14, pp. $327-341,2006$.

[17] Cirillo C. \& K. Axhausen, 'Evidence on the distribution of values of travel time savings from a six-week diary', Transportation Research Part A: policy and practice, 40 (5), pp. 444-457, 2006.

[18] Kaufmann, V., Re-thinking mobility. Contemporary Sociology, Aldershot, Ashgate, 109p, 2002.

[19] Ye X., R. Pendyala \& G. Gottardi, 'An exploration of the relationship between mode choice and complexity of trip chaining patterns', Transportation Research Part B: Methodological, 41 (1), pp. 96 - 113, 2007.

[20] De Vasconcellos E.A., 'Urban change, mobility and transport in São Paulo: three decades, three cities', Transport Policy, 12, pp. 91 - 104, 2005.

[21] O'Fallon C., C. Sullivan \& D. Hensher, 'Constraints affecting mode choices by morning car commuters', Transport Policy, 11 (1), pp. 17 - 29, 2004. 
[22] De Witte, A., C. Macharis \& O. Mairesse, 'How persuasive is free public transport? A survey among commuters in the Brussels-Capital Region', Transport Policy, 15, pp. 216-224, 2008.

[23] Ben-Akiva M. \& S. Lerman, 'Some estimation results of a simultaneous model of auto ownership and mode choice to work', Transportation, 3 (4), pp. $357-376,1974$.

[24] Goodwin, P., Cairns, S., Dargay, J., Hanly, M., Parkhurst, G., Stokes, G. \& P. Vythoulkas, 'Changing travel behaviour', Script of presentation given at the Bloomsbury Theatre, London, ESRC Transport Studies Unit, University College London, 48p, $2004 b$.

[25] Brown, B., Werner C. \& N. Kim, 'Personal and contextual factors supporting the switch to transit use: evaluating a natural transit intervention', Analyses of Social Issues and Public Policy, 3 (1), pp. 139 $160,2003$.

[26] Schwanen T., M. Dijst \& F. Dieleman, 'Leisure trips of senior citizens: determinants of modal choice', Tijdschrift voor economische en sociale geografie, 92, pp. 347 - 360, 2001.

[27] Bhat C., 'Work travel mode choice and number of non-work commute stops', Transportation Research Part B: Methodological, 31 (1), pp. 41-54, 1997.

[28] Nurul Habib K. M., N. Day \& E. Miller, 'An investigation of commuting trip timing and mode choice in the Greater Toronto Area: Application of a joint discrete-continuous model', Transportation Research Part A, 43, pp. $639-653,2009$.

[29] Pickery, J., 'Pendelgedrag en attitudes tegenover aspecten van het mobiliteitsbeleid in Vlaanderen', In: Lemaître, J. and J. Pickery (Eds.) Vlaanderen gepeild, Ministerie van de Vlaamse Gemeenschap, Brussels, pp. 131-161, 2005.

[30] Scheiner J. \& C. Holz-Rau, 'Travel mode choice: affected by objective or subjective determinants?', Transportation, 34 (4), pp. 487 - 511, 2007.

[31] Van Acker, V., B. Van Wee \& F. Witlox, 'When Transport Geography Meets Social Psychology: Toward a Conceptual Model of Travel Behaviour', Transport Reviews, pp. 1 - 22, 2010.

[32] De Palma A. \& Rochat D., 'Mode choices for trips to work in Geneva: an empirical analysis', Journal of Transport Geography, 8, pp. 43 - 51, 2000.

[33] Van de Walle, S. \& T. Steenberghen, 'Space and time related determinants of public transport use in trip chains', Transportation Research Part A, 40, pp. 151-162, 2006.

[34] Annema J., 'Weerstanden van verplaatsingen: tijd, kosten en moeite', In: Van Wee, B. \& M. Dijst (Eds.) Verkeer en vervoer in hoofdlijnen, Couthino, Bussum, pp. 97 - 117, 2002.

[35] Currie G. \& A. Delbosc, 'Exploring the trip chaining behaviour of public transport users in Melbourne', Transport Policy, 18 (1), pp. 204 - 210, 2011. 
[36] Verplanken, B., Aarts, H. \& A. Van Knippenberg, 'Habit, information acquisition, and the process of making travel mode choices', European Journal of social psychology, 27, pp. 539-560, 1997.

[37] Rietveld P., 'Non-motorised modes in transport systems: a multimodal chain perspective for The Netherlands', Transportation Research Part D, 5, pp. $31-36,2000$. 